\title{
La inscripción mural como política: (contra) poder en el grafiti de octubre de 2019
}

\section{Mural inscription as politics: (counter) power in October 2019 graffiti}

DOI: https://doi.org/10.29166/tyc.v1i22.2944

\section{Vinicio Ruperto Benalcázar Jácome}

Investigador en temas relacionados al ámbito de la cultura y la visualidad. Docente y mediador pedagógico en procesos educativos no formales. Cronista fotográfico de realidades populares y marginales. Realizador audiovisual interesado en la producción documental fotográfica y cinematográfica. Crítico de la circulación de sentidos imperantes en el modelo capitalista.

Correo: viniciobenalcazar@gmail.com

\section{Resumen}

Los primeros días de octubre de 2019 se desarrolló una de las más grandes movilizaciones de las últimas décadas en el país. El presente estudio se ocupa de examinar la intervención a través de inscripciones gráficas durante la protesta. Se revisa la participación política que tuvo el grafiti durante el levantamiento popular en Quito. Este ensayo expone la articulación de lo visual a un proceso social para reflexionar en torno a la política y la visualidad. El texto explora la disputa de sentidos que se desarrolla en el seno de la producción de procesos visuales contemporáneos como el grafiti.

Palabras clave: comunicación visual, visualidad, cultura visual, grafiti, levantamiento de octubre 2019.

\section{Abstract}

The first days of October 2019 saw the development of one of the largest mobilizations of the last decades in the country. The present study is concerned with examining the intervention with graphic inscriptions in those days of protest. It reviews the political participation that graffiti had during the popular uprising in Quito. This essay exposes the articulation of the visual to a social process in order to reflect on politics and visuality. The text explores the dispute of senses that takes place within the production of contemporary visual processes such as graffiti.

Keywords: visual communication, visuality, visual culture, graffiti, October 2019 uprising. 


\begin{abstract}
Una sola vez escribiste una frase, con tiza negra: A mí también me duele. No duró dos horas, y esta vez la policía en persona la hizo desaparecer. Después solamente seguiste haciendo dibujos.
\end{abstract}

(Cortázar, 2018, p. 479)

El artista que no siente las agitaciones, las inquietudes, las ansias de su pueblo y de su época, es un artista de sensibilidad mediocre, de comprensión anémica.

(Mariátegui, 1977, p. 58)

Una inscripción en la pared limita, marca, signa, nomina, enuncia. Se utiliza para expresar. Se expresa para manifestar. Durante las movilizaciones de octubre de 2019 en Ecuador, fue común ver los muros convertidos en canales para exteriorizar demandas. Si bien el interés de la cobertura mediática y del registro visual estaba centrado en las acciones que giraban en torno a la protesta, los muros no pasaron desapercibidos por la recurrente presencia de grafías e íconos. Esas paredes, que formaban parte del escenario de la protesta, acompañaban las actividades de los participantes mientras se producía la manifestación y, luego de las jornadas, permanecieron como testimonio de los hechos. Es decir, las inscripciones murales se constituyeron en un elemento adicional al desarrollo de la coyuntura. Es precisamente respecto a esto que el presente estudio reflexiona, enfocándose en la visualidad y el uso político de los muros durante las protestas del llamado Estallido (Iza, Tapia \& Madrid, 2020) de octubre en Ecuador. Tomando en cuenta que el grafiti en algunas de sus variantes se mantiene como una expresión periférica para ciertos sectores, la propuesta específica es revisar si la producción visual (grafiti) generada en el levantamiento popular de octubre del 2019 en Ecuador, es una evidencia de que, desde la visualidad, se pueden establecer otras formas de presencia política desde los márgenes. Es necesario considerar que para avanzar en esta intención, por una parte, se requiere revisar las siguientes categorías: cultura visual planteada por Nicholas Mirzoeff (2016a) (2016b) (2003) y Fernando Hernández (2005); política y mirada de Mieke Bal (2016); y guerra de imágenes de Serge Gruzinski (2012). Por otra parte, en cuanto a la estructura narrativa, este ensayo abordará la problemática en 3 momentos: descripción de contextos, desarrollo epistemológico de la visualidad y un tercer momento analítico metodológico. Además, para efectos instrumentales, se recurre a una muestra de 6 imágenes producidas en los días de las protestas. Un pequeño registro fotográfico, que forma parte de un archivo más extenso, pero debido a la delimitación temática no se utiliza en su totalidad.

La visualidad es un terreno vigente y en desarrollo del que es posible participar para poner en tensión un fenómeno como el del grafiti. Tomando en cuenta que "el crecimiento de las tecnologías de la representación y sus medios, así como las nuevas funciones que las imágenes poseen en la cultura contemporánea han creado objetos visuales de los que no se ocupan ninguna disciplina habitual" (Contreras, 2017, p. 484), es pertinente rastrear una producción visual específica, para articularla a las relaciones que su producción y circulación detonan. En consecuencia, el presente trabajo pretende consolidar un proceso sistemático de reflexión para sumar al desarrollo de la epistemología visual contemporánea. Es decir, este estudio no concluye en estas páginas, sino que convoca al diálogo crítico y al ejercicio reflexivo posterior en los múltiples ámbitos de la visualidad. 


\section{Contextos temporales, culturales y}

\section{sociales de una visualidad}

El rastro original del grafiti, sin que esto suponga ninguna novedad, se ubica en las inscripciones encontradas en las cavernas de Lascaux y Altamira. Esas marcas no eran más que intervenciones visuales sobre una superficie. Una serie de trazos dibujados que dejaron evidencia de ciertas presencias temporales. La capacidad expresiva de esas grafías se hace palpable en su potencial testimonial y representacional en el tiempo, desde su origen hasta la actualidad. En los términos que corresponde al presente trabajo, al grafiti se lo asocia a dos formas de interacción con el entorno: como inscripción enunciativa explícita, y como un elemento gráfico mural que supone mayor complejidad en su decodificación. En ese sentido, se lo puede considerar, en términos generales, como "texto a la vez verbal y visual, que puede ser leído y contemplado como imagen" (Ortega, 1999, p. 22). En el primer caso se alude a los diversos escritos de los que se puede extraer algún tipo de expresión decodificable. El segundo caso se refiere a ciertos "elementos visuales con los que convivimos en nuestro transitar diario y que comúnmente plantean dificultad de comprensión: letras, números, nombres, que [...] conviven y se disputan la visualidad de la ciudad" (Benalcázar, Arguello \& Ramírez, 2019, p. 10). En términos contemporáneos más específicos, el grafiti del primer caso tiene su raigambre en las paredes de Mayo del 68 en Francia. Las consignas que formaban parte de la protesta encontraron en los muros el mejor soporte para su difusión. Por otra parte, la raíz del grafiti del segundo caso se la puede ubicar en Estados
Unidos durante los años 60. Una serie de nombres empiezan a aparecer pintados sobre las paredes de ciudades como Filadelfia, Nueva York y Manhattan. Surge una expresión visual que aparece en las urbes, y es asociada al hip hop y al contexto reivindicativo de ciertos sectores sociales emergentes en ese momento.

El aparecimiento en Ecuador de estas líneas del grafiti responde a contextos sociales y temporales distintos. La primera, con una evidente adscripción enunciativa, aparece como resultado de la confluencia política de ciertos sectores sociales. Es común reconocer a Eugenio Espejo como el primer "graffitero que grabó consignas de libertad en las paredes coloniales de la monástica ciudad quiteña" (Ortega, 1999, p. 40) en la segunda mitad del siglo XVIII. Además, los distintos sucesos políticos de mediados del siglo XX en Latinoamérica son fuente para el surgimiento de este tipo de grafiti. La guerra, las dictaduras, los anhelos de libertad y la influencia de los procesos revolucionarios en el mundo promovieron su desarrollo. Es un tipo de grafiti que, debido a esos acontecimientos, enfatiza en las consignas políticas y poéticas. En los años 80, como resultado de las condiciones sociales, del accidentado retorno a la democracia y de la actuación del Estado como agente represor, los actores políticos recurren al grafiti como instrumento para expresar sus demandas públicamente. Por otra parte, el arribo al país del grafiti asociado al hip hop se produce como resultado de los procesos migratorios e influjo de la naciente industria cultural del rap. En los años 80 llega a Guayaquil, para los 90 a Quito (Benalcázar et al., 2019), coincidiendo su etapa de gran desarrollo con el inicio del nuevo milenio. A diferencia del grafiti expresamente enun- 
ciativo, este se enfoca en la delimitación territorial que los sujetos rayan en las paredes. Los nombres individuales o colectivos demarcan la pertenencia y definen la presencia en la ciudad. Ambos tipos de grafiti se proyectan públicamente, consideran la importancia de revelar la voz, ya que, recogiendo los planteamientos del muralismo, "conviene atacar la ejecución de murales exteriores, hacia la calle, frente al tránsito de las multitudes" (Siqueiros, 1979, p. 34). La conjunción de estos tipos de grafiti se hizo evidente en las manifestaciones de octubre de 2019 en Ecuador. La inscripción visual marcó los muros y provocó la coexistencia de "diversos relatos, plasmados en grafiti [...] elaboraciones más políticas, como: 'Capital, plusvalía, mueran con la burguesía'; otros económicas: 'Abajo el paquetazo', e incluso hubo los que banalizaron al sistema político representativo: 'Gran huevada ser Presidente [de la República]'” (Iza et al., 2020, p. 140), este tipo corresponde al grafiti con intereses enunciativos explícitos. Por otra parte, también estuvieron presentes los que desde su asociación visual con el hip hop aparecieron en las paredes con las leyendas "Únete pueblo", "Resiste", "No al paquetazo", "No FMI", entre otros.

El preámbulo de las jornadas sucedió en la noche del martes 1 de octubre de 2019, cuando el presidente ecuatoriano Lenin Moreno, en cadena nacional, informó un paquete de medidas económi$\operatorname{cas}^{1}$. Como consecuencia de este anuncio hubo una respuesta significativa y se inició una jornada de movilización en varias ciudades del país. La medida que motivó mayor rechazo en la población fue el anuncio de la eliminación del subsidio a los combustibles. Luego de 11 días, el gobierno, debido a la presión social en las calles, se vio obligado a retroceder en sus intenciones y derogó el Decreto 883. Los resultados fueron cientos de personas detenidas, miles de heridos, varios muertos y numerosas denuncias de violaciones a los Derechos Humanos. En este contexto de movilización, se observaron varias formas de participación. La presencia fue multitudinaria y de modos muy variados, tanto de manera tangible en la calle, como de manera virtual a través de las redes sociales. Entre todas las formas de protesta que se evidenciaron, llamaba la atención una en particular: la intervención visual con grafiti. Las paredes fueron uno de los canales a través de los cuales se expresaron las demandas y el sentir de la población ante las medidas implementadas por el gobierno. Como resultado de este proceso existió una prolífica producción visual de la que hay varios registros circulando en diversas plataformas de internet. Esa producción visual no fue el resultado de eventos aislados, sino que respondió a unas relaciones entre los diferentes participantes del proceso. Tomando en cuenta el concepto de cultura visual, es posible pensar que "ensamblamos una visión del mundo que resulta coherente con lo que sabemos y ya hemos

1 Las medidas implementadas fueron: liberación del precio de los combustibles a través del Decreto ejecutivo 883 ; aumento de 15 dólares para 300 mil familias por medio de diferentes bonos; eliminación o reducción de aranceles para maquinaria, equipos y materias primas agrícolas e industriales; eliminación de aranceles a la importación de celulares, computadoras, tabletas; USD 1000 millones para créditos hipotecarios desde noviembre, a una tasa del 4,99\%; y, los contratos ocasionales en el sector público se renovarían con $20 \%$ menos de remuneración. 
experimentado" (Mirzoeff, 2016a, p. 20), es decir, los sucesos que giran en torno a la visualidad son el resultado de una reapropiación de las prácticas circundantes en el entorno social y personal. Por lo tanto, las producciones visuales generadas durante la movilización de octubre responden a esa mirada afectada por la coyuntura. En ese sentido, para avanzar a la exploración de la problemática relacionada con la visualidad producida en los muros de octubre, es necesario revisar las categorías de cultural visual, política e imágenes, como elementos articuladores y configuradores de aquella visualidad.

\section{Basamento epistemológico de la imagen}

Asistimos a un momento de reconfiguración de la mirada. No solamente observamos, nos relacionamos con lo que vemos. Esos vínculos que establecemos a partir del ejercicio de mirar constituyen lo que se denomina cultura visual. Más allá de pensar únicamente en los objetos externos, es la posibilidad de articular la mirada, ya que, "no es simplemente la suma de todo lo que ha sido hecho para ser visto, como los cuadros o las películas. Una cultura visual es la relación entre lo visible y los nombres que damos a lo visto" (Mirzoeff, 2016a, p. 19). Es un régimen articulado de sujetos, objetos, representaciones y formas de ver, ya que, "cuando miramos (y producimos) las manifestaciones que forman parte de la cultura visual no estamos sólo mirando al mundo, sino a las personas y sus representaciones y las consecuencias que tienen sobre sus posicionalidades sociales" (Hernández, 2005, p. 29). En ese sentido, esa trama relacional se teje con la inter- vención de elementos múltiples en una "estructura interpretativa fluida, centrada en la comprensión de la respuesta de los individuos y los grupos a los medios visuales de comunicación" (Mirzoeff, 2003, p. 21). Es decir, los componentes que operan en la cultura visual no maniobran solos, se articulan en la interacción con otros. Responden a unas configuraciones en medio de sistemas de representación, que son los que demarcan la significación que atribuyen los sujetos a través de la mirada.

La irrupción de la visualidad en la escena política supone posibilidades de participación, lo que Mieke Bal (2016) denomina agencia visual. La mirada es un evento que conlleva procesos yuxtapuestos, ya que "es un acto de interpretación, la interpretación puede influir en la manera de ver y, por lo tanto, de imaginar posibilidades de cambio" (p. 43). En consecuencia, lo que vemos, al relacionarse en el proceso de la mirada, desarrolla producciones simbólicas reformuladas. Esto viabiliza la transformación y reconfiguración de lo que se abstrae a partir del ejercicio mismo de mirar lo que se constituye en una lucha discursiva. Es decir, una disputa por el sentido visual, donde "el primer problema político del texto [en tanto visualidad] es, [...] quién y cómo decreta sus límites, quién y cómo administra su objetivación" (Abril, 2007, p. 232). Esta articulación de lo visual con su entorno surge a partir del planteamiento de que la relación de "la imagen con las preocupaciones del mundo presente constituye un acto de proyección más abierto y consciente de sí mismo" (Bal, 2016, p. 22). La imagen no es una contingencia solitaria, a la deriva de las voluntades expresivas, sino que opera dentro de regímenes que la delimitan. Por lo tanto, 


\begin{abstract}
el campo de la cultura visual está por lo general, formado por la visión de que los artefactos y su percepción son semejantes en relación con el contexto de sus límites [ya que] los artefactos de la visión están histórica, social y políticamente determinados y que no pueden estudiarse aislados de estos factores (Hernández, 2005, p. 15).
\end{abstract}

Esto promueve un ejercicio de participación basado en la correspondencia de lo visual con el entorno. Una forma de presencia política articulada al contexto, en tanto, la interpretación se constituye en la construcción de posibilidades de abstracción y la generación de cambios a partir de la mirada como parte de un proceso complejo.

La tercera categoría por revisar es la guerra de imágenes. En el marco de la cultura visual, la agencia política de las producciones permite pensar que "dicha guerra abarca, más allá de las luchas por el poder, temas sociales y culturales cuya amplitud actual y futura aún somos incapaces de medir" (Gruzinski, 2012, p. 11). Sin embargo, es posible al menos perfilar un acercamiento a lo que podría entenderse como esta tensión en el marco de la visualidad. En esa confrontación, la imagen no resulta un terreno pasivo ni mucho menos un remanso sin complejidades. Puede entenderse como la "guerra de ciframientos y resignificaciones de que está hecha la historia profunda de nuestros países [...] por la amalgama de imágenes que hacen y deshacen la significación" (Martín-Barbero, 2017, p. 48). Una disputa que supone la contradicción en el seno de la producción y la interpretación. En ese sentido, es posible renunciar "a hacer una descripción demasiado sistemática de la imagen y de su contexto por temor a perder de vista una realidad que sólo existe en su interacción" (Gruzinski,
2012, p. 14). Es decir, la significación arguye varias tensiones que solamente operan al momento de participar en el campo de la cultura visual. Tomando en cuenta esta perspectiva "la imagen desborda el mero campo semiótico para ser entendida como un discurso que es el escenario de una batalla descarnada" (León, 2015, p. 42). La pretensión lectora, que muchas veces se promueve al momento de abordar la visualidad, resulta una tarea limitada en relación al potencial que supone la imagen y sus conflictos, debido a que lo visual compensa "los riesgos de una comunicación lingüística poco satisfactoria" (Gruzinski, 2012, p. 57). Por lo que, superar las limitaciones que supone una interpretación rígida y lineal, al momento de interactuar con lo visual, provoca una ampliación de la mirada hacia terrenos que rebasan lo dicotómico en la relación del objeto y su significación.

\section{Registro como mediación para el estudio}

Para avanzar en el análisis, es necesario señalar que el presente trabajo tiene dos instancias de producción para su objeto de estudio: una que se refiere al grafiti (la obra) y otra al registro visual del mismo. Ambos recursos confluyen en temporalidad, ya que, su realización se ubica en la duración de las jornadas de protesta, es decir, un lapso específico de 11 días. En primera instancia está la intervención visual en los muros, y, en segunda, la documentación fotográfica. $\mathrm{Si}$ bien para efectos metodológicos se recurre a las fotografías tomadas en aquellos días, la reflexión considera también el proceso de producción y significación de dichas inscripciones. El instrumento visual resulta útil para graficar el análisis 


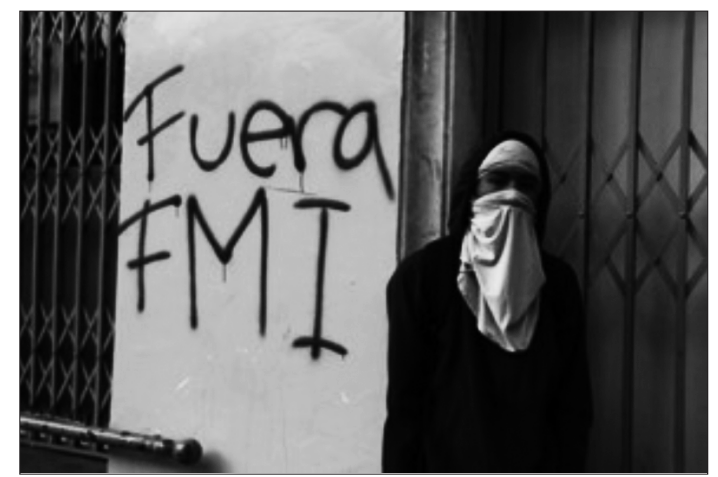

Figura 1. Fuera FMI

Fotografía por Gabriela Arguello.

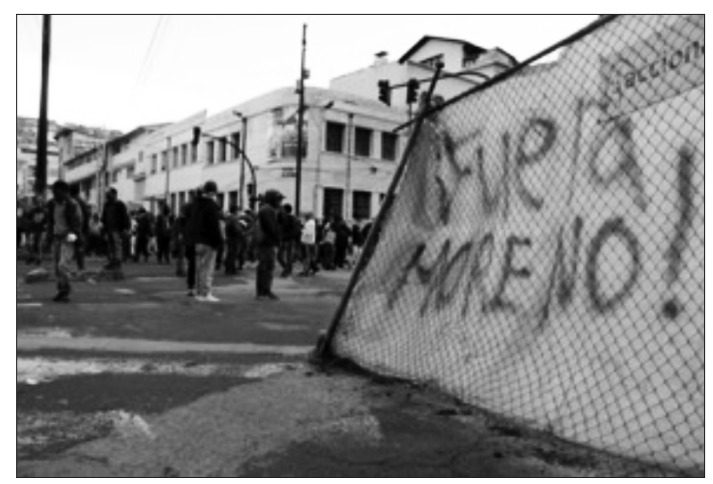

Figura 3: ¡Fuera Moreno!

Fotografía por Gabriela Arguello.

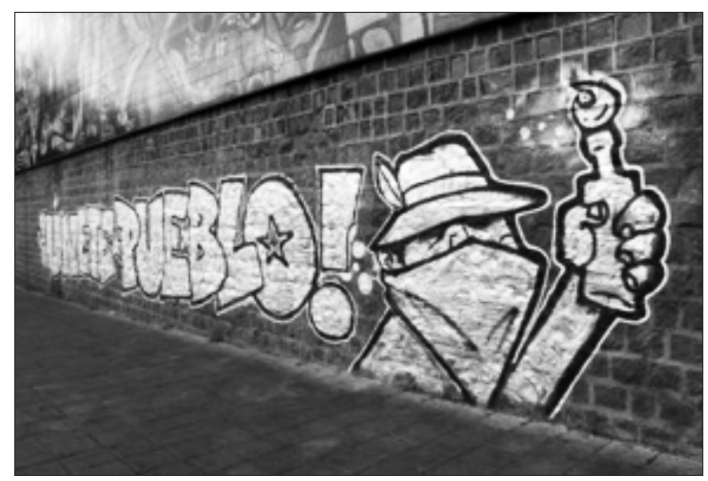

Figura 5. Únete pueblo

Fotografía por Andrés Ramírez.

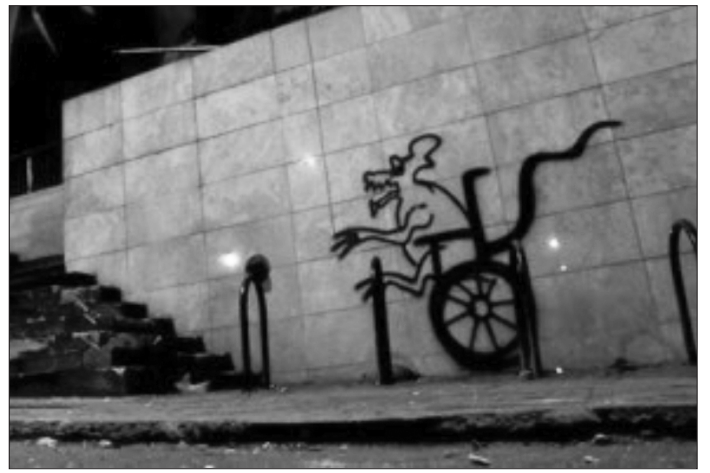

Figura 2: Rata

Fotografía por Gabriela Arguello.

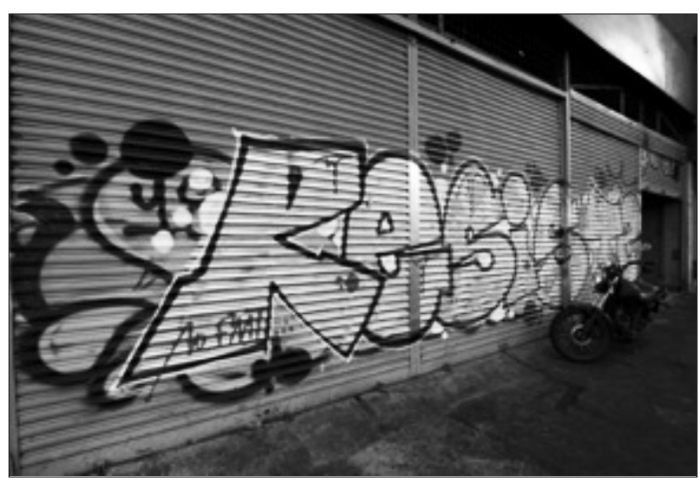

Figura 4. Resiste, No FMI

Fotografía por Andrés Ramírez.

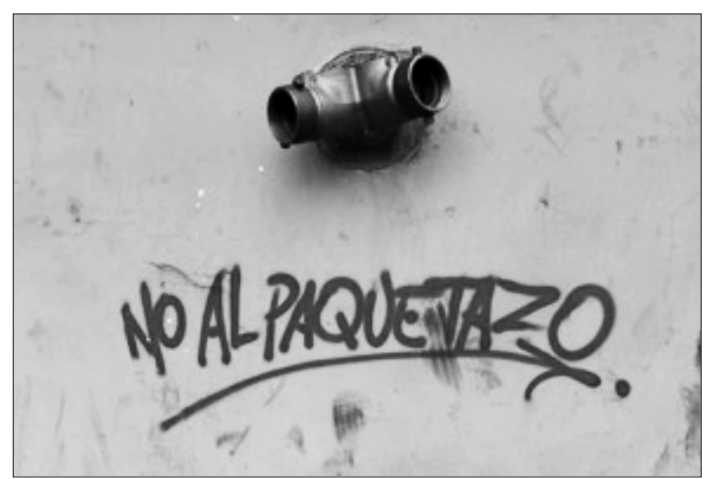

Figura 6. No al paquetazo

Fotografía por Andrés Ramírez. 
propuesto, sin dejar de lado el relacionamiento que forma parte de la visualidad producida sobre los muros. En consecuencia, para este estudio se utilizan 6 fotografías en las que se pueden observar varios aspectos de esa producción visual. Las imágenes están organizadas en dos grupos: uno corresponde a la enunciación explícita (figuras 1, 2 y 3), y otro al desarrollo expresivo del grafiti articulado al hip hop (figuras 4, 5 y 6). Considerando al grafiti como un signo cultural, la idea es abordarlo desde el análisis estructural, ya que "permite identificar los signos y códigos dentro del texto que, debajo de lo natural, ocultan lo social" (Alonso \& Fernández, 2006, p. 15). El estudio ubica la dimensión cultural en el análisis, más allá de la lectura de signos a través del lenguaje. Por tanto, la reflexión inserta la dimensión cultural al análisis visual, antes que la mera interpretación de signos presentes en el lenguaje, ya que "la imagen gráfica es recipiente del marco cultural en el cual funciona, y es en su uso y en la forma en que espera ser recibida donde se evidencian el diálogo, las intenciones y expectativas entre las distintas partes" (Ambrosini, 2015, p. 48). En ese sentido, se considera al grafiti a partir de su estatus de representación cultural, abordada desde el análisis visual.

En principio, la consigna enunciativa fundada en la memoria política del país, recurre al mensaje directo. Utiliza todos los recursos visuales a la mano, para potenciar lo que se requiere decir. Durante las protestas los muros se convirtieron en soportes para canalizar las demandas de manera explícita. Las reivindicaciones verbalizadas se trasladaron a las grafías inscritas en las paredes. Con palabras (figuras 1 y 3) o imágenes (figura 2) el mensaje era manifiesto. No había espacio para la reinterpretación de lo que exigían los participantes de la protesta. Eran inscripciones reconocibles, siempre y cuando se disponga de la capacidad lectora para decodificar texto o imagen. El uso de las palabras era abierto, sin ambigüedades ni mediaciones retóricas, Fuera FMI o Fuera Moreno, dejaban claro lo que se quería decir. Una rata en silla de ruedas puede tener cierto nivel retórico para detonar un proceso primario de asociación entre la figura del presidente de ecuatoriano (silla de ruedas) y el desprecio provocado en la población (rata). El texto visualizado en la manifestación fue el resultado de las inquietudes de un sector, que decidió transferir al soporte visual sus exigencias. Fue imperativo plasmar el signo en las paredes para dejar marcadas las huellas de los hechos. El muro deviene en canal y reproduce, en sitio, los discursos que circulan en la protesta. Este tipo de producciones pintadas en los lugares donde se desarrollaban las manifestaciones, se configuraron en elementos visuales complementarios al escenario de la protesta. Este tipo de grafiti convertido en un recordatorio de las exigencias y acompañando visualmente de manera presencial sincrónica a la memoria de un acontecimiento en desarrollo. De realización rápida, el grafiti enunciativo canalizó, sin mediaciones temporales, los anhelos de participación (presencia) del realizador individual o colectivo. Los sujetos que los realizaron permanecían omnipresentes física y temporalmente mientras persistiera la inscripción y la memoria de la protesta. En ese sentido, era el contexto lo que le daba significado a la inscripción visual.

Pintadas sobre paredes, puertas, mallas, telas y otras superficies, estas enunciaciones públicas exponían visual- 
mente la intención expresiva de sus autores. Resulta infructuoso rastrear la autoría individual de este tipo de inscripciones. Responden a una lógica colectiva. Quienes las pintan, aparecen y desaparecen con el mismo apremio que los textos grafiteados sobre los soportes. Son efímeros en el tiempo, pero su presencia es significativa mientras perduran en las inmediaciones de las protestas. Configuran el contexto visual que busca incentivar a la consecución de los objetivos que movilizan a los participantes. Recuerdan la motivación para asistir y convocarse. Posicionan explícitamente los discursos y las demandas. Activan a los sujetos que las observan mientras avanza la movilización. En definitiva, no son un mero elemento decorativo. Expresan visualmente un contenido ético dentro de la protesta y delimitan territorialmente las zonas en las que los acontecimientos forman parte de la participación política.

Por otra parte, el grafiti concebido como esa articulación en la que se encuentran las consignas con un desarrollo expresivo visual más complejo (figuras 4, 5 y 6), ya no es solamente la demanda "No al paquetazo" lo que aparece en las paredes, sino también la convocatoria "Únete pueblo" o el llamado a "Resistir". Este tipo de inscripción unifica formas estilísticas conjugadas con la textualidad de las grafías. La confluencia cultural de la técnica vinculada al hip hop, con la urgencia coyuntural del acontecimiento, expresa en el muro la participación, sin dejar de lado el cimiento identitario de la pertenencia al grafiti rapero. El tag (figura 6) y el quick piece (figuras 4 y 5) trasmutados en elementos visuales para interactuar en la protesta. En el marco de la cultura visual y la política de la mirada, esa relación con lo visible no es solamente mirar el objeto, sino las posiciones de los sujetos en la interacción con el contexto. También, ubicarse en esa trama relacional para la participación política con una forma gráfica, considerada muchas veces marginal, articulada a la coyuntura y actuando desde su propio fundamento. Esa presencia es la constitución de una enunciación visual que acoge el sentido de ese grafiti de expresión directa y lo conjuga con la gráfica críptica del grafiti enfocado en la pertenencia y la vinculación a la ciudad, provocando un tipo de inscripción que evoca la técnica singular del grafiti hip hop con elementos textuales explícitos. Esta forma visual, aparecida en los muros durante las protestas de octubre de 2019 en Ecuador, responde a las relaciones e interacciones con ese contexto específicamente. Su genealogía puede ser rastreada en los dos tipos de grafiti mencionados y su surgimiento responde a toda una configuración de elementos en diálogo.

En estos trazos perfilados se observa cierto manejo técnico y dominio de la herramienta. Si bien el soporte para la inscripción se ubica en las inmediaciones del perímetro de la protesta, el lugar específico para ubicarlo es un elemento preponderante, debido a que se busca visibilidad. La magnitud es otro factor importante. La gran proporción y el lugar (figuras 4 y 5) permiten el diálogo visual con los cuerpos que transitan en las inmediaciones de la movilización. La proporción reducida (figura 6) en cambio, requiere el acercamiento del observador. Por otra parte, las autorías, individuales o colectivas, son identificables si se tiene la capacidad de rastrear algún detalle formal de la obra. Una de las piezas recurre al recurso iconográfico (figura 5) para complementar la textualidad. El personaje representado, que puede ser identi- 
ficable para cualquiera de los asistentes a la protesta, cubre su rostro y sostiene en su mano una botella encendida. Este sujeto-ícono es un símil visual extraído de la movilización y transferido a la pared. Este tipo de grafiti recurre a los detalles para remarcar el énfasis visual. Destacan círculos, flechas, manchas, rayones, puntos y bordes delineados para que la visualidad en conjunto acompañe a la expresividad del texto.

\section{Diálogos sociales, culturales y políticos}

La cultura visual es el fundamento epistemológico que viabiliza la reflexión de este tipo de fenómenos. Su radio de acción prefigura una oportunidad para observar el amplio espectro de lo que comprende la mirada. Paredes pintadas, muros con leyendas, trazos sobre diferentes soportes no serían más que la simple suma de elaboraciones aisladas. Sin embargo, en el instante en que se expresan dentro de un sistema de relaciones, se complejizan esas presencias. Pasan a formar parte de un conjunto integrado por procesos históricos, sociales y culturales que materializan su significación. De manera muy simple, son tres los elementos que intervienen en el proceso de producción del grafiti: soporte, material y sujetos. Pero avanzando a una lectura un tanto más compleja, hay toda una trama en la que se desenvuelven. La coyuntura es el espacio que configura una particularidad detonante de significaciones. El lugar donde la agencia social del sujeto grafitero se resignifica en relación con la realidad circundante. La obra cobra valor en el mismo entramado relacional que participó de su producción. Es decir, los flujos sociales, culturales, pero, en este caso particular, sobretodo políticos, responden a un proceso mediante el cual la visualidad alude a la conjunción de diversos factores. Esto provoca su adscripción a un sistema de producciones, lecturas, interpretaciones, que van más allá que la sola literalidad enunciativa de la obra.

La articulación de la imagen con la sociedad en la que está inscrita se hace patente como un ejercicio de presencia política o como una expresión de disputa desde el margen. La agencia visual se podría entender como una trama de significados que no solo decoran, sino que responden a estructuras visuales en conflicto. El grafiti es una presencia constante en los muros, de manera particular en octubre de 2019. Esa presencia surge y se amplifica debido a que es el resultado de una producción transtemporal y de un acumulado relacional histórico. La política ecuatoriana de los años 80 aparece representada en la visualidad de las consignas. En ese sentido, las relaciones de la obra con el espacio de lo social confluyen en la visualidad de los muros como ejercicios en una perspectiva de contrapolítica y de contrapoder. Reconociendo que "la cultura visual es algo en lo que nos involucramos como una manera activa de provocar cambios, no solo una forma de ver lo que acontece" (Mirzoeff, 2016a, p. 22). Ese grafiti concebido como enunciado visual, proviene de una articulación cambiante y al integrarse al contexto de la protesta, provoca y acompaña la posibilidad de transformación de la misma visualidad y sus relaciones.

La tensión entre la participación convencional -por llamarla de alguna manera- y la presencia política desde el margen, en un contexto de movilización y protesta, expresa que existen distintas formas de articular relaciones con el 
poder. Si bien, "los graffitis aparecen para ser contemplados, leídos, borrados, manchados, alabados o silenciados" (Ortega, 1999, p. 42), la producción visual de las inscripciones murales en octubre de 2019 estableció formas de articulación más allá de la imagen en sí misma. No se sugiere que la producción visual opere de manera lineal, como en una relación de causaefecto. $\mathrm{Su}$ presencia no es para atender una necesidad de textualizar las consignas, sino para exponer una forma otra de relacionarse con la manifestación. El grafiti, como una pieza visual que incorpora la consigna a sus recursos, asimila y restituye un intercambio de sentidos entre la forma y el texto. La proyección de esa relación es significativa porque redimensiona el alcance de la misma demanda, amplifica su acción e incidencia, incorporando en esa dinámica a otros sectores, ya que "el terreno de la imagen no sólo ofrece una comodidad de comunicación y de acción. Abarca móviles más fundamentales, casi siempre implícitos" (Gruzinski, 2012, p. 58). Es decir, el rastro de esa presencia visual se ubica más allá de la inscripción, está en las relaciones de poder que establece en su interacción con el contexto en el cual se desarrolla.

Analizar desde la visualidad el levantamiento popular de octubre de 2019 permite rastrear las particularidades de una expresión cultural y sus articulaciones con lo político. Dentro de la protesta confluyen varios actores para intervenir desde sus propias lógicas. Los sectores que participan en el desarrollo de una coyuntura son múltiples y las formas de operar están matizadas por sus diferencias. Por lo tanto, es importante ubicar esos detalles (desde la visualidad) para clarificar las presencias en pro de la consecución de objetivos, al momento de construir plataformas comunes en una movilización social. Por otra parte, esta investigación se enfocó en el análisis de la visualidad a partir de la consideración del objeto en sus interrelaciones culturales. En ese sentido, el presente estudio prefiguró un método para el abordaje de fenómenos visuales similares. Se ubicaron las características de la cultura visual y sus articulaciones hacia la política de la visualidad. En contexto, el grafiti resultó en la confluencia de relaciones históricas que convergen en la participación coyuntural desde el presente. Es decir, el papel del grafiti y su presencia como expresión de la cultural visual.

Finalmente, la producción visual generada en octubre del 2019 en Ecuador expresa de manera patente que se pueden establecer otras formas de presencia política desde los márgenes. El levantamiento popular tuvo diversos actores, uno fue la inscripción mural como la conjugación de enunciación y visualización. Durante el desarrollo de los acontecimientos, este tipo de producción visual estableció diferentes formas para configurarse como articulador de sentidos. Los elementos visuales y técnicos, presentes en su realización, respondieron a la convergencia de múltiples factores técnicos, sociales, culturales, históricos y políticos. En primera instancia se constituyó en una presencia particular. Si bien el grafiti de tipo enunciativo textual (figuras 1, 2 y 3), estuvo presente, su participación responde a ciertas dinámicas preestablecidas en medio de la protesta. En cambio, el tipo de grafiti que tiene su raíz en el hip hop (figuras 4, 5y 6), fue una presencia nueva. Un articulador de sentidos en evidente participación política, a través de la constitución de una agencia visual expresada concretamente en los muros. Estas ins- 
cripciones establecieron una forma de relacionarse con los soportes en los que se materializaron. Las imágenes analizadas, sumadas al diálogo entre las diversas instancias y los diferentes elementos que in- tervienen en el proceso, constituyeron un ejercicio de contrapoder a partir de la participación política, desde lo textual hacia la visualidad periférica en medio de la misma protesta.

\section{Bibliografía}

Abril, G. (2007). Análisis crítico de textos visuales. Mirar lo que nos mira. Síntesis.

Alonso, L., \& Fernández, C. (2006). Roland Barthes y el Análisis del Discurso. Empiria. Revista de metodología de las Ciencias Sociales, 12, 11-35.

Ambrosini, J. D. (2015). La visualidad como objeto: El giro pictórico y los estudios de la cultura visual. Dixit, 22, 38-49. https://doi.org/10.22235/d.v0i22.380

Bal, M. (2016). Tiempos trastornados: Análisis, historias y políticas de la mirada (R. Llorente, Trad.). Ediciones Akal S.A.

Benalcázar, V., Arguello, G., \& Ramírez, A. (2019). Escritores de firma: Testimonio visual de una presencia urbana. Memoria de la visualidad grafiti en Quito (Proyectos de Investigación UASB, Sede Ecuador, p. 139). Universidad Andina Simón Bolívar, Sede Ecuador. http://repositorio.uasb.edu.ec/handle/10644/6663

Contreras, F. (2017). Estudio sobre los planteamientos teóricos y metodológicos de los Estudios Visuales. Arte, Individuo y Sociedad, 29(3), 483-499. https://doi.org/10.5209/ARIS.55559

Cortázar, J. (2018). Graffiti. En Cuentos completos 2 (Vol. 2, pp. 478-482). Titivillus.

Gruzinski, S. (2012). La guerra de las imágenes: De Cristóbal Colón a "Blade runner" (1492-2019) (J. J. Utrilla, Trad.). Fondo de Cultura Económica. http://www.digitaliapublishing.com/a/43129/

Hernández, F. (2005). ¿De Qué Hablamos Cuando Hablamos De Cultura Visual? Educação \& Realidade, 30(2), 9-34.

Iza, L., Tapia, A., \& Madrid, A. (2020). Estallido, la rebelión de octubre en Ecuador. Ediciones Red Kapari.

León, C. (2015). Regímenes de poder y tecnologías de la imagen, Foucault y los estudios visuales. post(s), 1. https://doi.org/10.18272/posts.v1i1.236

Mariátegui, J. C. (1977). El artista y la época (6a). Amauta.

Martín-Barbero, J. (2017). Visibilidad(es) y visualidad(es). Visibilidades latinoamericanas en el contexto hipervisual. En Ver con los otros: Comunicación intercultural (pp. 44-66). Fondo de Cultura Económica.

Mirzoeff, N. (2003). Una introducción a la cultura visual (P. García, Trad.). Ediciones Paidós Ibérica S.A.

Mirzoeff, N. (2016a). Cómo ver el mundo. Una nueva introducción a la cultura visual (P. Herminda, Trad.). Espasa Libros.

Mirzoeff, N. (2016b). El derecho a mirar. IC Revista Científica de Información y Comunicación, 13. https://icjournalojs.org/index.php/IC-Journal/article/view/358

Ortega, A. (1999). La ciudad y sus bibliotecas: El graffiti quiteño y la crónica costeña. Univ. Andina Simón Bolívar, Sede Ecuador.

Siqueiros, D. A. (1979). Como se pinta un mural (3a). Ediciones Taller Siqueiros. 